\title{
Recommendations for the Management of Patients With Systemic Rheumatic Diseases During the Coronavirus Disease Pandemic
}

Mi Ryoung Seo, M.D. ${ }^{1}$, Ji-Won Kim, M.D., Ph.D. ${ }^{2}$, Eun-Jung Park, M.D. ${ }^{3}$, Seung Min Jung, M.D., Ph.D. ${ }^{4}$, Yoon-Kyoung Sung, M.D., Ph.D., MPH ${ }^{5}$, Hyungjin Kim, M.D., Ph.D. ${ }^{6}$, Gunwoo Kim, M.D., Ph.D. ${ }^{7}$, Hyun-Sook Kim, M.D., Ph.D. ${ }^{8}$, Myeung-Su Lee, M.D., Ph.D. ${ }^{9}$, Jisoo Lee, M.D., Ph.D. ${ }^{10}$, Jian Hur, M.D., Ph.D. ${ }^{11}$, Bum Sik Chin, M.D., Ph.D. ${ }^{12}$, Joong Sik Eom, M.D., Ph.D. ${ }^{13}$, Han Joo Baek, M.D., Ph.D. ${ }^{1}$; The Korean College of Rheumatology Working Group

${ }^{1}$ Division of Rheumatology, Department of Internal Medicine, Gachon University College of Medicine, Gil Medical Center, Incheon, ${ }^{2}$ Division of Rheumatology, Department of Internal Medicine, Daegu Catholic University School of Medicine, Daegu, ${ }^{3}$ Division of Rheumatology, Department of Internal Medicine, National Medical Center, ${ }^{4}$ Division of Rheumatology, Department of Internal Medicine, College of Medicine, The Catholic University of Korea, ${ }^{5}$ Department of Rheumatology, Hanyang University Hospital for Rheumatic Diseases, ${ }^{6}$ Department of Medical Humanities, Samsung Medical Center, Sungkyunkwan University School of Medicine, Seoul, ${ }^{7}$ Division of Rheumatology, Department of Internal Medicine, Daegu Fatima Hospital, Daegu, ${ }^{8}$ Division of Rheumatology, Department of Internal Medicine, Soonchunhyang University Seoul Hospital, Seoul, ${ }^{9}$ Division of Rheumatology, Department of Internal Medicine, Wonkwang University Hospital, Iksan, ${ }^{10}$ Division of Rheumatology, Department of Internal Medicine, Ewha Womans University College of Medicine, Seoul, ${ }^{11}$ Division of Infectious Diseases, Department of Internal Medicine, Yeungnam University Medical Center, Daegu, ${ }^{12}$ Division of Infectious Diseases, Department of Internal Medicine, National Medical Center, Seoul, ${ }^{13}$ Division of Infectious Diseases, Department of Internal Medicine, Gachon University College of Medicine, Gil Medical Center, Incheon, Korea

Patients with systemic rheumatic diseases (SRD) are vulnerable for coronavirus disease (COVID-19). The Korean College of Rheumatology recognized the urgent need to develop recommendations for rheumatologists and other physicians to manage patients with SRD during the COVID-19 pandemic. The working group was organized and was responsible for selecting key health questions, searching and reviewing the available literature, and formulating statements. The appropriateness of the statements was evaluated by voting panels using the modified Delphi method. Four general principles and thirteen individual recommendations were finalized through expert consensus based on the available evidence. The recommendations included preventive measures against COVID-19, medicinal treatment for stable or active SRD patients without COVID-19, medicinal treatment for SRD patients with COVID-19, and patient evaluation and monitoring. Medicinal treatments were categorized according to the status with respect to both COVID-19 and SRD. These recommendations should serve as a reference for individualized treatment for patients with SRD. As new evidence is emerging, an immediate update will be required. (J Rheum Dis 2020;27:218-232)

Key Words. Coronavirus, SARS-CoV-2, Rheumatic diseases, Recommendations, Treatment

\section{INTRODUCTION}

Coronavirus disease (COVID-19), first reported in December 2019 in Wuhan, China, is caused by infection with the novel betacoronavirus, severe acute respiratory syndrome coronavirus 2 (SARS-CoV-2) [1]. Since then, it has spread rapidly, and a worldwide outbreak was noted in a few months. The World Health Organization (WHO) declared the COVID-19 outbreak a global pandemic on March 11, 2020 [2]. As of May 17, 2020, the WHO re-

Received : August 13, 2020, Revised : September 6, 2020, Accepted : September 7, 2020

Corresponding to : Han Joo Baek (D http://orcid.org/0000-0001-7558-052X

Division of Rheumatology, Department of Internal Medicine, Gachon University College of Medicine, Gil Medical Center, 21 Namdong-daero 774beon-gil, Namdong-gu, Incheon 21565, Korea. E-mail : baekhj@gilhospital.com

This article is co-published by the Korean Journal of Internal Medicine and Journal of Rheumatic Diseases.

Copyright (c) 2020 by The Korean College of Rheumatology.

This is an Open Access article, which permits unrestricted non-commerical use, distribution, and reproduction in any medium, provided the original work is properly cited. 
ported that the cumulative number of COVID-19 cases in the world was 4.6 million and that more than $310,000 \mathrm{pa}-$ tients had died [3]. In Korea, the first case of COVID-19 was identified on January 20, 2020; subsequently, a substantial outbreak was noted in Korea [4]. The outbreak has been relatively well-regulated by the implementation of appropriate preventive measures by the government and active participation of the public and medical professionals. However, new cases continue to be reported in Korea, and the COVID-19 pandemic has been scattered worldwide. Vaccines or therapeutic drugs for COVID-19 have not been developed to date.

Patients with systemic rheumatic diseases (SRD), such as rheumatoid arthritis (RA) and systemic lupus erythematosus (SLE) are prone to infection because the immune system dysfunction is noted in patients with SRD and immunosuppressive medications are usually used for these patients [5-10]. In addition, patients with SRD often present with several comorbidities [11] that are known to be risk factors for COVID-19 [12,13]. Therefore, patients with SRD are a vulnerable population during the COVID-19 pandemic, which should be considered as one of the major threats to public health worldwide.

The Korean College of Rheumatology (KCR) recognized the urgent need to develop recommendations for rheumatologists and other physicians caring for patients with SRD during the COVID-19 pandemic. The working group was organized to review the evidence and draft preliminary statements of recommendation. The final statements were determined by expert panel consensus using a modified Delphi approach and approved by the KCR. The recommendations consist of general principles and individual items of recommendation for the management of SRD during the COVID-19 outbreak. These recommendations were based on the evidence available in literature at that time and the consensus of experts.

\section{PROCESS FOR THE DEVELOPMENT OF THE RECOMMENDATIONS}

\section{Working group}

The working group comprised 11 rheumatologists and 3 infectious disease specialists. They participated in establishing the recommendation development plan, deciding the purpose and scope, selecting key questions, searching and reviewing the literature, and drafting the preliminary statements.

\section{Purpose and scope}

The recommendations were developed for the management of adult patients with SRD during the COVID-19 pandemic. Provision of recommendations for the treatment of COVID-19 was beyond our study scope. SRD refer to autoimmune or immune-mediated rheumatic diseases, including RA, SLE, spondyloarthritis, and other such diseases. The recommendations were intended for rheumatologists and other physicians who manage patients with SRD. The health questions for developing the recommendations included general principles, preventive measures against COVID-19, treatment of stable or active SRD patients without COVID-19, treatment of SRD patients with COVID-19, and assessment and monitoring of SRD. The medications used for patients with SRD were classified, as follows: 1) nonsteroidal anti-inflammatory drugs (NSAIDs), 2) glucocorticoids, 3) conventional synthetic disease-modifying antirheumatic drugs (csDMARDs), 4) biological DMARDs (bDMARDs), 5) targeted synthetic DMARDs (tsDMARDs), and 6) denosumab.

\section{Literature search and review}

The working group searched for and reviewed the relevant literature archived in the MEDLINE database (via PubMed) as of April 23, 2020, for the following domains: 1) general principles, 2) preventive measures and monitoring, 3) NSAIDs, 4) glucocorticoids, 5) csDMARDs, 6) bDMARDs, 7) tsDMARDs, and 8) denosumab. We limited our search to publications in the English or Korean language. The clinical guidelines or recommendations for managing patients with COVID-19 or SRD that were developed by international or national medical societies were included. The working group selected literature relevant to health questions, reviewed and summarized the contents, and evaluated the evidence level according to the Oxford Centre for Evidence-Based Medicine [14].

\section{Formulation of statements and consensus}

The working group formulated the preliminary statements consisting of four general principles and thirteen recommendations. The consensus of the final statements was established using the modified Delphi approach as described in the RAND/University of California, Los Angeles (UCLA) Appropriateness Method [15]. The voting panel comprised 27 rheumatologists and 3 infectious disease specialists, which included members of the working group. The survey was performed online with internet-based software. The voting panel members were 
asked to rate their level of agreement for the appropriateness of seventeen preliminary statements using a 9-point numeric scale (1 [strongly disagree] to 9 [strongly agree]). The statements were classified into three levels of appropriateness, using the following definitions: appropriate (median rating of $7 \sim 9$, without disagreement), uncertain (median rating of $4 \sim 6$ or any median with disagreement), and inappropriate (median rating of $1 \sim 3$, without disagreement). The definition of disagreement was based on the Interpercentile Range Adjusted for Symmetry (IPRAS) method described in the RAND/ UCLA appropriateness method [15]. All draft statements were agreed to be appropriate by the panel, and then these final statements were officially endorsed as recommendations for the management of patients with SRD during the COVID-19 pandemic by the KCR (Table 1).

\section{RECOMMENDATIONS FOR THE MANAGEMENT OF PATIENTS WITH SRD DURING THE COVID-19 PANDEMIC}

\section{General principles}
1) Patients with SRD are at a higher risk for severe COVID-19 (level of evidence [LoE]: 5)

Among COVID-19 patients, elderly patients and pa-

Table 1. Recommendations for the management of patients with SRD during the COVID-19 pandemic

\begin{tabular}{lrr}
\hline & General principles & Appropriateness* \\
\cline { 2 - 3 } & Median & $\geq 7 / 9(\%)$ \\
\hline 1. Patients with SRD are at a higher risk for severe COVID-19. & 8.5 & 73 \\
2. Immediate diagnostic testing is required for patients with SRD with suspected COVID-19. & 9 & 100 \\
3. Shared decision-making is fundamental, and the disease status, comorbidities, and presence or \\
absence of COVID-19 should be considered when treating patients with SRD.
\end{tabular}

Recommendations

1. Regular exercise within the personal space, smoking cessation, and vaccinations against 9 influenza and pneumococcus are encouraged in patients with SRD.

2. For stable SRD patients without COVID-19, current medication, including glucocorticoids, 99100 DMARDs, and other immunosuppressants, may be continued.

3. NSAIDs may be used, if indicated, for SRD patients, except for patients with severe COVID-19. 8400

4. A. Glucocorticoids, at the minimum effective dose required, can be used to control disease $9 \quad 100$ activity in active SRD patients without COVID-19.

B. Even in patients with COVID-19, current treatment with glucocorticoids for SRD should not $\quad 9 \quad 100$ be abruptly terminated.

5. A. csDMARDs can be initiated or used for active SRD patients without COVID-19. B. In patients with COVID-19, treatment with csDMARDs, except for hydroxychloroquine and $\quad 7.5 \quad 70$ sulfasalazine, should be temporarily terminated.

6. A. bDMARDs can be initiated or used for active SRD patients without COVID-19.

B. In patients with COVID-19, treatment with bDMARDs, except for interleukin-6 inhibitors, 88 should be temporarily terminated.

7. A. The initiation of tsDMARDs may be postponed until the cessation of the COVID-19 pandemic 887 if an alternative therapy is available.

B. In patients with COVID-19, treatment with tsDMARDs should be temporarily discontinued. $8 \quad 8 \quad 80$

8. Continuing the use of denosumab is suggested for patients with osteoporosis. $\quad 8 \quad 100$

9. The intervals for and methods of monitoring the disease status and drug toxicities may be $9 \quad 100$ appropriately adjusted for patients with stable SRD.

SRD: systemic rheumatic diseases, COVID-19: Coronavirus disease 2019, DMARDs: NSAIDs nonsteroidal anti-inflammatory drugs, csDMARDs: conventional synthetic SRD systemic rheumatic diseases, bDMARDs: biological disease-modifying antirheumatic drugs, tsDMARDs: targeted synthetic DMARDs. *Appropriateness was evaluated according to RAND/University of California, Los Angeles (UCLA) appropriateness method (Appropriate [A] was defined as a median rating of $7 \sim 9$ without disagreement). 
tients with heart or lung disease have higher morbidity and mortality rates [12,13,16-19]. Although precise data are not available, patients with SRD may have a high risk for developing severe COVID-19 owing to immune dysfunction noted in SRD and common cardiovascular and lung disease comorbidities. Immunosuppressive therapies, including glucocorticoids and DMARDs can make them more prone to severe or fatal disease [7,8,10,20-28]. Therefore, patients with SRD should be considered a high-risk group for severe COVID-19 and preferred for evaluation and examination.

2) Immediate diagnostic testing is required for patients with SRD with suspected COVID-19 (LoE: 5)

Early detection is essential for treating and preventing the spread of COVID-19 [29-32]. In the area of COVID-19 outbreak, any patient with acute onset of fever, respiratory symptoms, such as cough, phlegm, and dyspnea, and/or other constitutional symptoms, including arthralgia and myalgia, should be suspected of experiencing COVID-19 [16]. In patients with SRD, however, the symptoms of infection can be masked by the effects of the anti-inflammatory drugs or glucocorticoids that they are receiving. In up to $20 \%$ of the patients with SRD who had COVID-19, fever did not appear as an initial symptom $[17,18,33]$. In addition, some manifestations of COVID-19, like arthralgia and cytokine storm, are similar to those of SRD [34]. Therefore, the diagnosis of COVID-19 in patients with SRD is challenging when only symptoms and signs are considered. A diagnostic test, such as polymerase chain reaction (PCR) for COVID-19, is immediately required when COVID-19 is clinically suspected in a patient with SRD.

3) Shared decision-making is fundamental, and the disease status, comorbidities, and presence or absence of COVID-19 should be considered when treating patients with SRD (LoE: 5)

Shared decision-making with patients is fundamental during the COVID-19 pandemic partly because of the current insufficient evidence on COVID-19 and inevitable uncertainty in medical decisions. Patients should be able to obtain appropriate medical advice and are encouraged to participate in treatment decision-making. When treating patients with SRD, the current status of underlying SRD and their comorbidities and the presence or absence of COVID-19 should be considered [35-38]. Patients with COVID-19 should be treated in cooperation with the relevant infectious disease specialists or considered to be referred to them [29,39-42].

4) Patients should be provided with information regarding public preventive measures against COVID-19, such as washing hands, wearing a face mask, and social distancing (LoE: 2 [washing hands], 4 [wearing a mask], 5 [social distancing])

The transmission of COVID-19 mainly occurs by close contact through respiratory droplets, by direct contact with infected persons, or by contact with contaminated objects and surfaces [43]. Therefore, in order to prevent infection and transmission of the virus, it is essential to keep strict hand hygiene [44-46], wear a face mask [47-52], and practice social distancing [53]. The systematic review has shown that respiratory virus spread can be prevented by hygiene measures such as handwashing [45]. Although wearing face masks in non-pandemic settings did not show a statistically significant reduction of acute respiratory viral infection cases [47], it is now considered a reasonable measure to reduce virus transmission during the COVID-19 pandemic $[48,51,52]$. In a randomized controlled trial, coronavirus was detected in the exhaled breath of $30 \% \sim 40 \%$ of participants without face masks, while it was not detected in participants wearing face masks [50]. Social distancing is one of the best ways to reduce close contact and to prevent the spread of the virus [53]. Patients should be provided with information on public precautionary measures and encouraged to comply with them for protecting themselves and their societies from COVID-19 [54-59].

\section{Recommendations}

Recommendation 1. Regular exercise within the personal space, smoking cessation, and vaccinations for influenza and pneumococcus are encouraged in patients with SRD (LoE: 5 [exercise], 4 [smoking], 5 [vaccination])

Exercise may lower the disease activity of SRD and improve the function and the participation of patients with SRD [60]. International societies have strongly recommended exercise for patients with SRD, such as RA and spondyloarthritis $[36,61]$. Considering that exercise is effective, safe, and can be easily performed, it is also recommended appropriately for public health $[62,63]$. However, prolonged high-intensity exercise is not advisable because it can lead to immunosuppression for hours [64]. A well-ventilated personal space is suitable for exercise, 
considering the risk of COVID-19 transmission. Performing exercise outdoor while maintaining appropriate physical distance from other people may also be suitable $[65,66]$.

Generally, smoking is a risk factor for acute respiratory disease [67]. Regarding COVID-19, smoking has been reported to be associated with an increased risk of infection and worse outcomes [68-70]. Smoking can cause or worsen comorbidities such as cardiovascular disease, respiratory diseases, and diabetes mellitus [71,72]. Therefore, smoking cessation has been proposed as a major public health measure in response to the COVID-19 pandemic [73]. Smoking reportedly has harmful effects on the human immune system [74]. In terms of SRD, smoking is the most potent environmental risk factor for the development of RA [75] and is also associated with the development of SLE [76]. Smoking may decrease the therapeutic responsiveness of DMARDs, such as antimalarial agents $[77,78]$. As patients with SRD also have a high risk of cardiovascular disease, smoking cessation is generally recommended by international societies $[36,61,79]$.

Influenza infection may concurrently develop in COVID-19 patients [80], and one or more other pathogenic infections have been detected in 21\% of the COVID-19 patients [81]. Data from China showed that secondary bacterial infections were detected in $50 \%$ of the patients with COVID-19 who died $[12,82]$. Therefore, a co-infection may be a potential risk factor that may lead to fatal consequences [83]. In addition, the severity of COVID-19 was reportedly low in patients who were vaccinated against influenza [84]. In general, administration of influenza and pneumococcal vaccines is strongly recommended for patients with SRD [85]. Prevention of respiratory diseases through vaccination can reduce not only fatality rates associated with COVID-19 but also the burden on the medical system during the COVID-19 pandemic.

\section{Recommendation 2. For stable SRD patients without} COVID-19, current medication, including glucocorticoids, DMARDs, and other immunosuppressants, may be continued (LoE: 4)

High disease activity in patients with SRD may act as a risk factor for infection [9], and strict control of SRD activity, in general, is more important even if the infection risk may increase with the use of immunosuppressive medications, including glucocorticoids and DMARDs. Sudden drug withdrawal may exacerbate SRD. This can result in the requirement of an increased dose of immunosuppressive agents such as glucocorticoids, which may increase the risk of infection with COVID-19 $[86,87]$. As long-term use of glucocorticoids may lead to inhibition of the hypothalamic-pituitary-adrenal axis, the sudden cessation of glucocorticoids can cause adrenal crisis [88-90]. Thus, current medications for SRD, including glucocorticoids, DMARDs, and other immunosuppressive drugs, may be continued in stable SRD patients without evidence of COVID-19, and these medications should not be abruptly terminated.

Recommendation 3. NSAIDs may be used, if indicated, for SRD patients, except for patients with severe COVID-19 (LoE: 4)

NSAIDs are used in patients with SRD for controlling symptoms or some disease activity or both. The WHO initially warned that the use of NSAIDs in patients with COVID-19 might be risky, based on a French study on the use of ibuprofen in patients with chickenpox and pneumonia [91]. Paracetamol was suggested as the primary drug for controlling the symptoms of COVID-19 [92-95]. However, owing to the lack of further studies supporting it, this suggestion was withdrawn [96-98]. Discontinuation of NSAIDs in patients with SRD may aggravate disease activity, leading to an increase in the risk of infection [99]. Thus, NSAIDs may be used if indicated in SRD patients with COVID-19, except for in cases of severe disease. NSAIDs may have a deleterious effect on patients presenting with severe COVID-19 with multi-organ dysfunction [18].

Recommendation 4. A. Glucocorticoids, at the minimum effective dose required, can be used to control disease activity in active SRD patients without COVID-19 (LoE: 5). B. Even in patients with COVID-19, current treatment with glucocorticoids for SRD should not be abruptly terminated (LoE: 5)

Even during the COVID-19 pandemic, glucocorticoids can be used to control disease activity in SRD patients without COVID-19. However, systemic glucocorticoid therapy may increase the risk of infection in a dose-dependent manner. It is associated with an increased risk of reactivation of herpes zoster virus, severe bacterial infections, and opportunistic infections [10,27,100]. As glucocorticoids can cause several harmful side effects, besides infection, the minimum effective dose should be used.

There are controversies regarding the effects of systemic glucocorticoids on patients with respiratory viral diseases. 
Systemic glucocorticoid use was associated with increased mortality in patients with influenza [101] and delayed viral clearance in patients with Middle Eastern Respiratory Syndrome Coronavirus (MERS-CoV) [102]. Although evidence regarding the benefits of glucocorticoid use is not available, systemic glucocorticoid therapy has been widely used for the treatment of SARS-CoV infection [103]. COVID-19 can cause an explosive immune response, such as a cytokine storm, leading to immune-mediated tissue injury. Systemic glucocorticoids have been used in these patients, although the therapeutic effects of systemic glucocorticoids are not clear [104]. A recent meta-analysis reported that glucocorticoids do not affect the mortality among patients with COVID-19 [105]. In addition, systemic glucocorticoids currently used for SRD should not be terminated abruptly because the risk of adrenal crisis, flare of SRD or both may outweigh the potential advantages associated with glucocorticoid withdrawal. High doses of glucocorticoids may be permitted for SRD patients who have a severe or vital organ-threatening disease even when they are experiencing COVID-19.

Recommendation 5. A. csDMARDs can be initiated or used for active SRD patients without COVID-19 (LoE: 5). B. In patients with COVID-19, treatment with csDMARDs, except for hydroxychloroquine and sulfasalazine, should be temporarily terminated (LoE: 4 [hydroxychloroquine], 5 [sulfasalazine])

csDMARDs, including methotrexate, leflunomide, chloroquine (CQ)/hydroxychloroquine (HCQ), and sulfasalazine (SSZ), are usually used for controlling disease activity and preventing structural damage in patients with SRD. It has been reported that csDMARDs are not associated with an increased risk of infection [8], and high disease activity is a risk factor of infection in patients with RA $[6,106]$. It is reasonable to use csDMARDs to control the disease in active SRD patients without COVID-19.

As both SRD and the use of immunosuppressant drugs are risk factors for infection in patients with SRD $[7,25,106,107]$, the temporary discontinuation of immunosuppressant drugs is generally recommended in SRD patients with severe infection [108]. In cancer patients with repeated cycles of chemotherapy, the clinical outcome of COVID-19 was significantly worse $[109,110]$, and the hazard ratio of chemotherapy within 14 days prior to the documentation of COVID-19 for severe complications was 4.079 (95\% confidence intervals [CIs] $1.086 \sim$
15.322) [110]. These findings indicate that immunosuppressive therapy may worsen the clinical outcome of COVID-19. Thus, it is recommended to temporarily discontinue csDMARDs with immunosuppressive potential in SRD patients infected with COVID-19. Since CQ/HCQ and SSZ may not have an immunosuppressive effect, they may be used in SRD patients with COVID-19.

Recommendation 6. A. bDMARDs can be initiated or used for active SRD patients without COVID-19 (LoE: 5). B. In patients with COVID-19, treatment with bDMARDs, except for interleukin- 6 inhibitors, should be temporarily terminated (LoE: 5)

bDMARDs, inhibiting tumor necrosis factor (TNF) or other proinflammatory cytokines, have a significant effect on improving disease activity, symptoms, and functions of patients with SRD refractory to first-line therapy $[35,36,38,111,112]$. However, incidental infection is a major concern for patients undergoing bDMARD therapy. bDMARDs are associated with an increased, but variable, risk of infection with Mycobacterium and other opportunistic pathogens [113]. The risk of severe infection requiring hospitalization is substantially higher in patients receiving bDMARD therapy than in those receiving csDMARD therapy [114]. Use of bDMARDs can reactivate viral diseases, such as hepatitis B and $\mathrm{C}$, although the outcomes of bDMARD therapy range from no association between bDMARD use and incidence of herpes zoster infection to low incidence of infection $[26,115,116]$. As in the case of csDMARD therapy, bDMARDs can be used for patients with newly diagnosed or active SRD patients, if indicated according to the current guidelines for patients without COVID-19, because uncontrolled disease activity poses a high risk of infection. In SRD patients with COVID-19, it is reasonable to discontinue bDMARDs temporarily except for interleukin-6 (IL-6) inhibitors. IL-6 inhibitors have been shown to be effective in the treatment of severe COVID-19 patients in several studies [117-120]. Patients with severe COVID-19 have sometimes deteriorated into cytokine syndromes, in which IL-6 is the primary cytokine in cytokine storm syndrome, so IL- 6 inhibitors are assumed effective in inflammatory conditions caused by COVID-19 [121,122]. IL-6 inhibitors may also be considered in COVID-19 cases with respiratory failure, rapid exacerbation, or high serum levels of IL-6 [123]. Thus, IL-6 inhibitors may be continued in active SRD patients with COVID-19. 
Recommendation 7. A. The initiation of tsDMARDs may be postponed until the cessation of the COVID-19 pandemic if an alternative therapy is available (LoE: 5). B. In patients with COVID-19, treatment with tsDMARDs should be temporarily discontinued (LoE: 5)

tsDMARDs that are currently used for patients with SRD include tofacitinib, baricitinib, and upadacitinib. Among them, baricitinib, an inhibitor of both Janus kinase 1 (JAK1) and Janus kinase 2 (JAK2), was proposed as a therapeutic agent for COVID-19, especially for patients with severe disease because it inhibits adaptor-associated protein kinase 1 (AAK1), a regulator of SARS-CoV-2 endocytosis $[124,125]$. However, the JAK inhibitors may not be safe for use because inhibition of JAK and the subsequent activator of the transcription protein signaling pathway can affect the activity of interferon- $\alpha$, resulting in a decrease in the immune response to viral infection [126-129]. In early or asymptomatic patients with COVID-19, interferon- $\alpha$ may play an important role in overcoming the disease [127].

According to clinical data, tofacitinib has a serious risk of infection when compared to bDMARDs and is associated with a two-fold higher risk of herpes zoster versus all bDMARDs [130]. In particular, older patients (>65 years of age) treated with tofacitinib had a significantly higher risk of severe and fatal infections than those who were treated with TNF inhibitors [131].

Considering the possible risk associated with the use of the JAK inhibitor for the viral disease, we suggest that beginning with tsDMARD therapy in active SRD patients be postponed until the cessation of the COVID-19 pandemic and an alternative therapy other than tsDMARDs be preferred. If a patient is infected with COVID-19, tsDMARDs should be temporarily discontinued.

Recommendation 8. Continuing the use of denosumab is suggested for patients with osteoporosis (LoE: 5)

Denosumab is a human monoclonal antibody that binds to the receptor activator of nuclear factor kappa-B ligand (RANKL). Denosumab is used for treating osteoporosis and preventing fractures. Some effects of RANKL inhibition on immune function have been reported in animal models, and RANKL-RANK interaction might modify immune responses in the skin through an effect on the intensity of the inflammatory response [132-135]. Serious adverse events of infections have been noted in subjects receiving denosumab in some clinical trials [136-138]. However, an analysis of the serious infection events in a large clinical trial showed no clear clinical pattern to suggest a relationship with time or duration of exposure to denosumab [137]. There are some emerging data that discontinuation of denosumab leads to a rebound increase in the risk of multiple vertebral fractures [139-141]. Fractures occurred 8 to 16 months after the last dose [139]. Considering the risk of fractures, we suggest that the use of denosumab for SRD patients with osteoporosis be continued and the dosing intervals of denosumab do not exceed 8 months.

Recommendation 9. The intervals for and methods of monitoring the disease status and drug toxicities may be appropriately adjusted for patients with stable SRD (LoE: 5)

Patients with newly diagnosed or active SRD should be evaluated for their disease status and drug toxicities periodically based on the current recommendations [35,36,38,111]. Frequent visits to hospitals might expose the patients to a risk of infection during the COVID-19 pandemic. For patients with stable SRD, the intervals and methods for monitoring the disease status and the safety of the patients can be adjusted appropriately to minimize unnecessary hospital visits [93].

\section{CONCLUSION}

COVID-19, an infectious disease that has turned into a global pandemic, is causing unprecedented damage to humans and societies. It poses a substantial threat to not only global public health but also vulnerable populations. Infection often leads to morbidity and mortality in patients with SRD; thus, the COVID-19 pandemic is a major concern for physicians treating SRD and for patients with SRD.

We have developed treatment recommendations for rheumatologists and other physicians who manage patients with SRD during the COVID-19 pandemic. Four general principles and thirteen recommendations, including the preventive measures against COVID-19, medicinal treatment for SRD, and patient evaluation and monitoring, were established.

Patients with SRD are vulnerable for COVID-19. Elderly patients and patients with underlying medical conditions are at higher risk of severe COVID-19 [21]. The hospitalization and mortality rates associated with COVID-19 increase with older age [13,21]. The US CDC (Centers for Disease Control and Prevention) has stated that chronic 
kidney disease, chronic obstructive pulmonary disease, immunocompromised state, obesity, severe heart condition, sickle cell disease, and type 2 diabetes mellitus are related to an increased risk of severe COVID-19 [21]. Although SRD is not stated to be clearly associated with an increased risk of COVID-19 by the US CDC, evidence has indicated that patients with SRD are associated with an increased risk of infection [7,142-144]. This may be because of the substantial dysfunction of the innate and adaptive immunity in SRD pathogenesis $[143,145,146]$. In addition, patients with SRD are prescribed immunosuppressive agents, including glucocorticoids and DMARDs, which increase the risk of infection $[24,147]$. Lymphocytopenia and corticosteroid therapy $(>10 \mathrm{mg}$ prednisolone equivalent per day) have been reported as predictive factors of infection requiring hospitalization in patients receiving chronic immunosuppressive therapy [23]. With respect to COVID-19, immunosuppression and lymphocytopenia were associated with critical disease $[22,148]$.

Most recent studies confirmed an increased risk of severe COVID-19 in patients with SRD. From the results of the COVID-19 Global Rheumatology Alliance Registry, the mortality rate of rheumatic patients with COVID-19 (9\%) was higher than that of the general population with COVID-19 (5.7\% according to the WHO on June 12 , 2020), and glucocorticoid exposure ( $\geq 10 \mathrm{mg}$ prednisolone equivalent per day) was associated with hospitalization [149]. A large-scale study from the UK showed that common autoimmune diseases such as RA and SLE were risk factors for COVID-19 related death [150]. Moreover, compared with the reference population, COVID-19 has occurred more frequently in patients with rheumatic diseases (odds ratio 1.32, 95\% CIs 1.15 1.52), especially in patients receiving bDMARDs or tsDMARDs as reported in a Spanish retrospective study conducted in seven hospitals [151].

COVID-19 is a highly infectious disease, especially during the early stage, and is associated with significant morbidity and fatality rates. Thus, early diagnosis and patient isolation are essential for the management of patients with COVID-19 and for preventing viral spread. However, during the early stages of the COVID-19 pandemic, the strategies for diagnostic testing differed among the nations, depending on the capacities of the medical system, availability of diagnostic kits, and perspective of health policies. For example, the use of diagnostic tests was limited to severely ill patients in Italy and the UK, while ag- gressive testing was performed in Korea for early disease diagnosis $[152,153]$. Diagnostic testing for COVID-19 is usually indicated for patients suspected to have been exposed to COVID-19 and presenting with fever or respiratory symptoms, such as cough, phlegm, and sore throat. However, in Korea, physicians can order COVID-19 diagnostic testing for patients with suspected COVID-19 even when they do not present with all the aforementioned symptoms [29]. Owing to active testing, tracing, and implementation of an isolation strategy for patients with COVID-19, the COVID-19 outbreak has been relatively well-controlled in Korea.

The diagnosis of COVID-19 is challenging in patients with SRD. In SRD patients, systemic and respiratory symptoms of viral infections can be mistaken for those of underlying diseases or associated lung disease. In addition, the effects of anti-inflammatory drugs may mask symptoms, such as fever [33]. Delay in the diagnosis may lead to worse outcomes in SRD patients vulnerable for COVID-19. COVID-19 cannot be excluded based on symptoms in patients with SRD. Testing for early diagnosis of COVID-19 should not be delayed for SRD patients with suspected viral infection.

Public preventive measures against COVID-19, such as washing hands, wearing a mask, and social distancing, are critical for preventing infection and the spread of the virus. There were controversies on the effectiveness of wearing a face mask in the early days of the COVID-19 pandemic. However, a recent systematic literature review showed that wearing a mask can significantly reduce the risk of COVID-19 [154]. We recommend wearing a face mask, washing hands frequently, and social distancing to prevent the development of COVID-19 in vulnerable patients.

In these recommendations, medicinal treatments are categorized according to the states of both COVID-19 and SRD. In the absence of COVID-19, it is recommended to maintain current treatment in patients with stable SRD. In active SRD patients without COVID-19, medications except for tsDMARDs may be started or used if indicated. In the case of tsDMARDs, we suggest using alternative treatment options considering the risks of JAK inhibitors during the COVID-19 outbreak. However, tsDMARDs may be used for active SRD patients, if options other than tsDMARDs are not available. If SRD patients are infected with COVID-19, immunosuppressive drugs, except for glucocorticoids, CQ/HCQ, SSZ, and IL-6 inhibitors, should be discontinued temporarily because of the risk to 
exacerbate the viral disease. According to these recommendations, early diagnosis or exclusion of COVID-19 is crucial because the presence or absence of COVID-19 determines the initial clinical pathway for drug therapy.

Patients may have difficulty in visiting hospitals during the outbreak of COVID-19. Hospital visits can increase the risk of exposure to COVID-19. Therefore, during the COVID-19 pandemic, it may be necessary to extend the monitoring intervals or introduce the means of seeing the patients in a non-face-to-face way. Telemedicine was partly performed over the phone in Daegu, Korea, while the city was on near lockdown due to the COVID-19 outbreak.

Although increasing evidence is available regarding COVID-19, high-quality evidence is currently lacking. There is marked uncertainty on the management strategy for patients with COVID-19. Most of the evidence supporting these recommendations is low-level and indirect. Some recommendations have been formulated based mainly on expert opinions and precautionary principles. As considerable scientific evidence on COVID-19 is now emerging, these recommendations will require an appropriate revision in the not too distant future. Until then, we hope that these recommendations will serve as a helpful reference for the individualized management of patients with SRD.

\section{ACKNOWLEDGMENTS}

The authors would like to thank all members of the voting panel: Wan-Uk Kim, Seoul St. Mary's Hospital, The Catholic University of Korea; Tae-Hwan Kim, Hanyang University Hospital for Rheumatic Diseases; Hyun Ah Kim, Hallym University Sacred Heart Hospital; Namgyu Park, Dr. Park's Clinic; Sung-Hwan Park, Seoul St. Mary's Hospital, Catholic University Medical College; Jung-Soo Song, Chung-Ang University Hospital; Seung-Cheol Shim, Chungnam National University Hospital; Sang-Il Lee, Gyeongsang National University and Gyeongsang University Hospital; Sang-Heon Lee, Konkuk University Hospital Sung Won Lee, Dong-A University College of Medicine; Shin-Seok Lee, Chonnam National University Medical School \& Hospital; Young Ho Lee, Korea University Medical Center; Eun Bong Lee, Seoul National University College of Medicine; Chang Keun Lee, University of Ulsan, College of Medicine, Asan Medical Center; Hoon-Suk Cha, Samsung Medical Center, Sungkyunkwan University; Seung-Jae Hong, Kyung Hee University
Medical Center, Kyung Hee University.

\section{CONFLICT OF INTEREST}

No potential conflict of interest relevant to this article was reported.

\section{AUTHOR CONTRIBUTIONS}

Among the authors, M.R.S. and H.J.B. were in charge of conception and design of study, acquisition of data, analysis and/or interpretation of data, drafting and revising the manuscript. J.W.K., E.J.P., S.M.J., Y.K.S., H.K., H.S.K., and J.L. were responsible for design of study, acquisition of data, analysis and/or interpretation of data, and drafting the manuscript. G.K., M.S.L., J.A.H., B.S.C., and J.S.E contributed conception and design of study, and revising the manuscript critically for important intellectual content.

\section{REFERENCES}

1. Zhu N, Zhang D, Wang W, Li X, Yang B, Song J, et al.; China Novel Coronavirus Investigating and Research Team. A novel coronavirus from patients with pneumonia in China, 2019. N Engl J Med 2020;382:727-33.

2. World Health Organization. WHO announces COVID-19 outbreak a pandemic [Internet]. Geneva: World Health Organization, c2020 [cited 2020 Mar 12]. Available from: https://www.euro.who.int/en/health-topics/healthemergencies/coronavirus-covid-19/news/news/2020/ 3/who-announces-covid-19-outbreak-a-pandemic.

3. World Health Organization. Coronavirus disease (COVID-19) pandemic [Internet]. Geneva: World Health Organization, c2020 [cited 2020 May 17]. Available from: https://www. who.int/emergencies/diseases/novel-coronavirus-2019.

4. Kim JY, Choe PG, Oh Y, Oh KJ, Kim J, Park SJ, et al. The first case of 2019 novel coronavirus pneumonia imported into Korea from Wuhan, China: implication for infection prevention and control measures. J Korean Med Sci 2020;35:e61.

5. Ceribelli A, Motta F, De Santis M, Ansari AA, Ridgway WM, Gershwin ME, et al. Recommendations for coronavirus infection in rheumatic diseases treated with biologic therapy. J Autoimmun 2020;109:102442.

6. Au K, Reed G, Curtis JR, Kremer JM, Greenberg JD, Strand $\mathrm{V}$, et al.; CORRONA Investigators. High disease activity is associated with an increased risk of infection in patients with rheumatoid arthritis. Ann Rheum Dis 2011;70: 785-91.

7. Franklin J, Lunt M, Bunn D, Symmons D, Silman A. Risk and predictors of infection leading to hospitalisation in a large primary-care-derived cohort of patients with inflammatory polyarthritis. Ann Rheum Dis 2007;66: 308-12. 
8. Lacaille D, Guh DP, Abrahamowicz M, Anis AH, Esdaile JM. Use of nonbiologic disease-modifying antirheumatic drugs and risk of infection in patients with rheumatoid arthritis. Arthritis Rheum 2008;59:1074-81.

9. Jani M, Barton A, Hyrich K. Prediction of infection risk in rheumatoid arthritis patients treated with biologics: are we any closer to risk stratification? Curr Opin Rheumatol 2019;31:285-92.

10. Youssef J, Novosad SA, Winthrop KL. Infection risk and safety of corticosteroid use. Rheum Dis Clin North Am 2016;42:157-76, ix-x.

11. Gabriel SE, Michaud K. Epidemiological studies in incidence, prevalence, mortality, and comorbidity of the rheumatic diseases. Arthritis Res Ther 2009;11:229.

12. Zhou F, Yu T, Du R, Fan G, Liu Y, Liu Z, et al. Clinical course and risk factors for mortality of adult inpatients with COVID-19 in Wuhan, China: a retrospective cohort study. Lancet 2020;395:1054-62.

13. Ruan Q, Yang K, Wang W, Jiang L, Song J. Clinical predictors of mortality due to COVID-19 based on an analysis of data of 150 patients from Wuhan, China. Intensive Care Med 2020;46:846-8

14. Centre for Evidence-Based Medicine. OCEBM levels of evidence [Internet]. Oxford: Centre for Evidence-Based Medicine, c2016 [cited 2020 Apr 23]. Available from: https://www.cebm.net/2016/2005/ocebm-levels-of-evidence/.

15. Fitch K, Bernstein SJ, Aguilar MD, Burnand B, LaCalle JR, Lazaro P, et al. The RAND/UCLA appropriateness method user's manual [Internet]. Santa Monica (CA): RAND Corporation, c2001 [cited 2020 Apr 23]. Available from: http://www.rand.org/pubs/monograph_reports/ MR1269.html.

16. Guan WJ, Ni ZY, Hu Y, Liang WH, Ou CQ, He JX, et al.; China Medical Treatment Expert Group for Covid-19. Clinical characteristics of coronavirus disease 2019 in China. N Engl J Med 2020;382:1708-20.

17. Huang C, Wang Y, Li X, Ren L, Zhao J, Hu Y, et al. Clinical features of patients infected with 2019 novel coronavirus in Wuhan, China. Lancet 2020;395:497-506.

18. Wang D, Hu B, Hu C, Zhu F, Liu X, Zhang J, et al. Clinical characteristics of 138 hospitalized patients with 2019 novel coronavirus-infected pneumonia in Wuhan, China. JAMA 2020;323:1061-9.

19. Wu Z, McGoogan JM. Characteristics of and important lessons from the coronavirus disease 2019 (covid-19) outbreak in China: summary of a report of 72314 cases from the Chinese Center for Disease Control and Prevention. JAMA 2020;323:1239-1242.

20. European League Against Rheumatism. EULAR calls on governments in Europe to recognize the most vulnerable during COVID-19 [Internet]. Kilchberg: European League Against Rheumatism, c2020 [cited 2020 Apr 23]. Available from: https://www.eular.org/call_on_governments.cfm.

21. Centers for Disease Control and Prevention. People who are at increased risk for severe illness [Internet]. Atlanta (GA): Centers for Disease Control and Prevention, c2020 [cited 2020 Jun 25]. Available from: https://www.cdc. gov/coronavirus/2019-ncov/need-extra-precautions/ people-at-higher-risk.html.

22. Feng Y, Ling Y, Bai T, Xie Y, Huang J, Li J, et al. COVID-19 with different severities: a multicenter study of clinical features. Am J Respir Crit Care Med 2020;201:1380-8.

23. Glück T, Kiefmann B, Grohmann M, Falk W, Straub RH, Schölmerich J. Immune status and risk for infection in patients receiving chronic immunosuppressive therapy. J Rheumatol 2005;32:1473-80.

24. Salliot C, Gossec L, Ruyssen-Witrand A, Luc M, Duclos M, Guignard S, et al. Infections during tumour necrosis factor-alpha blocker therapy for rheumatic diseases in daily practice: a systematic retrospective study of 709 patients. Rheumatology (Oxford) 2007;46:327-34.

25. Listing J, Gerhold K, Zink A. The risk of infections associated with rheumatoid arthritis, with its comorbidity and treatment. Rheumatology (Oxford) 2013;52:53-61.

26. Singh JA. Infections with biologics in rheumatoid arthritis and related conditions: a scoping review of serious or hospitalized infections in observational studies. Curr Rheumatol Rep 2016;18:61.

27. Pappas DA, Hooper MM, Kremer JM, Reed G, Shan Y, Wenkert D, et al. Herpes zoster reactivation in patients with rheumatoid arthritis: analysis of disease characteristics and disease-modifying antirheumatic drugs. Arthritis Care Res (Hoboken) 2015;67:1671-8.

28. Bechman K, Subesinghe S, Norton S, Atzeni F, Galli M, Cope AP, et al. A systematic review and meta-analysis of infection risk with small molecule JAK inhibitors in rheumatoid arthritis. Rheumatology (Oxford) 2019;58:1755-66.

29. The Korean Society of Infectious Diseases. Korean Society of Infectious Diseases recommendations for COVID-19 [Internet]. Seoul: The Korean Society of Infectious Diseases, c2020 [cited 2020 May 28]. Available from: http://www.ksid.or.kr/rang_board/list.html? num =3684 \&code $=$ ncov_guide_do.

30. World Health Organization. Laboratory testing for coronavirus disease 2019 (COVID-19) in suspected human cases: interim guidance, 2 March 2020 [Internet]. Geneva: World Health Organization, c2020 [cited 2020 Apr 23]. Available from: https://apps.who.int/iris/handle/10665/ 331329.

31. European Centre for Disease Prevention and Control. Case definition for coronavirus disease 2019 (COVID-19), as of 29 May 2020 [Internet]. Solna: European Centre for Disease Prevention and Control, c2020 [cited 2020 May 29] Available from: https://www.ecdc.europa.eu/en/casedefinition-and-european-surveillance-human-infectionnovel-coronavirus-2019-ncov.

32. Centers for Disease Control and Prevention. Overview of testing for SARS-CoV-2 (COVID-19) [Internet]. Atlanta (GA): Centers for Disease Control and Prevention, c2020 [cited 2020 Jul 17]. Available from: https://www.cdc.gov/ coronavirus/2019-ncov/hcp/clinical-criteria.html? CDC_AA_refVal=https\%2013A\%2012F\%2012Fwww.cd c.gov\%2012Fcoronavirus\%2012F2019-ncov\%2012Fclini cal-criteria.html

33. Gianfrancesco MA, Hyrich KL, Gossec L, Strangfeld A, Carmona L, Mateus EF, et al.; COVID-19 Global Rheumatology Alliance Steering Committee. Rheumatic disease and COVID-19: initial data from the COVID-19 Global Rheumatology Alliance provider registries. Lancet Rheumatol 2020;2:e250-3

34. Misra DP, Agarwal V, Gasparyan AY, Zimba O. Rheumatologists 
perspective on coronavirus disease 19 (COVID-19) and potential therapeutic targets. Clin Rheumatol 2020;39: 2055-62.

35. Smolen JS, Landewé RBM, Bijlsma JWJ, Burmester GR, Dougados M, Kerschbaumer A, et al. EULAR recommendations for the management of rheumatoid arthritis with synthetic and biological disease-modifying antirheumatic drugs: 2019 update. Ann Rheum Dis 2020;79: 685-99.

36. van der Heijde D, Ramiro S, Landewé R, Baraliakos X, Van den Bosch F, Sepriano A, et al. 2016 update of the ASAS-EULAR management recommendations for axial spondyloarthritis. Ann Rheum Dis 2017;76:978-91.

37. Smolen JS, Schöls M, Braun J, Dougados M, FitzGerald O, Gladman DD, et al. Treating axial spondyloarthritis and peripheral spondyloarthritis, especially psoriatic arthritis, to target: 2017 update of recommendations by an international task force. Ann Rheum Dis 2018;77:3-17.

38. Fanouriakis A, Kostopoulou M, Alunno A, Aringer M, Bajema I, Boletis JN, et al. 2019 Update of the EULAR recommendations for the management of systemic lupus erythematosus. Ann Rheum Dis 2019;78:736-45.

39. World Health Organization. Clinical management of severe acute respiratory infection (SARI) when COVID-19 disease is suspected: interim guidance, 13 March 2020 [Internet]. Geneva: World Health Organization, c2020 [cited 2020 Apr 23]. Available from: https://apps.who.int/iris/handle/10665/331446.

40. National Health Service. Coronavirus guidance for clinicians and NHS managers [Internet]. Leeds: National Health Service, c2020 [cited 2020 May 18]. Available from: https://www.england.nhs.uk/coronavirus/.

41. Centers for Disease Control and Prevention. Interim clinical guidance for management of patients with confirmed coronavirus disease (COVID-19) [Internet]. Atlanta (GA): Centers for Disease Control and Prevention, c2020 [cited 2020 Apr 23]. Available from: https://www.cdc. gov/coronavirus/2019-ncov/hcp/clinical-guidance-management-patients.html.

42. National Institutes of Health. Coronavirus disease 2019 (COVID-19) treatment guidelines [Internet]. Bethesda (MD): National Institutes of Health, c2020 [cited 2020 Apr 23]. Available from: https://covid19treatmentguidelines. nih.gov/.

43. World Health Organization. Clinical management of COVID-19: interim guidance, 27 May 2020 [Internet]. Geneva: World Health Organization, c2020 [cited 2020 May 28]. Available from: https://apps.who.int/iris/handle/ $10665 / 332196$.

44. World Health Organization. Interim recommendations on obligatory hand hygiene against transmission of COVID-19 [Internet]. Geneva: World Health Organization, c2020 [cited 2020 Apr 23]. Available from: https://www.who.int/ publications/m/item/interim-recommendations-on-obligatoryhand-hygiene-against-transmission-of-covid-19.

45. Jefferson T, Del Mar CB, Dooley L, Ferroni E, Al-Ansary LA, Bawazeer GA, et al. Physical interventions to interrupt or reduce the spread of respiratory viruses. Cochrane Database Syst Rev 2011;2011:CD006207.

46. Ferner RE. Hand disinfectant and COVID-19 [Internet]. Oxford: Centre for Evidence-Based Medicine, c2020 [cited
2020 Apr 23]. Available from: https://www.cebm.net/ covid-19/hand-disinfectant-and-covid-19/.

47. Jefferson T, Jones M, Al Ansari LA, Bawazeer G, Beller E, Clark J, et al. Physical interventions to interrupt or reduce the spread of respiratory viruses. Part 1 - face masks, eye protection and person distancing: systematic review and meta-analysis. medRxiv 2020. DOI:10.1101/2020.03.30. 20047217.

48. Feng S, Shen C, Xia N, Song W, Fan M, Cowling BJ. Rational use of face masks in the COVID-19 pandemic. Lancet Respir Med 2020;8:434-6.

49. Bae S, Kim MC, Kim JY, Cha HH, Lim JS, Jung J, et al. Effectiveness of surgical and cotton masks in blocking SARS-CoV-2: a controlled comparison in 4 patients. Ann Intern Med 2020;173:W22-3.

50. Leung NHL, Chu DKW, Shiu EYC, Chan KH, McDevitt JJ, Hau BJP, et al. Respiratory virus shedding in exhaled breath and efficacy of face masks. Nat Med 2020;26: 676-80.

51. Howard J, Huang A, Li Z, Tufekci Z, Zdimal V, van der Westhuizen H, et al. Face masks against COVID-19: an evidence review. Preprints 2020. DOI:10.20944/preprints 202004.0203.v1.

52. Greenhalgh T, Schmid MB, Czypionka T, Bassler D, Gruer L. Face masks for the public during the covid-19 crisis. BMJ 2020;369:m1435.

53. Mahtani KR, Heneghan C, Aronson JK. What is the evidence for social distancing during global pandemics? [Internet]. Oxford: Centre for Evidence-Based Medicine, c2020 [cited 2020 Apr 23]. Available from: https://www. cebm.net/covid-19/what-is-the-evidence-for-social-distancing-during-global-pandemics/.

54. Choi S, Ki M. Estimating the reproductive number and the outbreak size of COVID-19 in Korea. Epidemiol Health 2020;42:e2020011.

55. Korea Centers for Disease Control and Prevention. Preventive measures againt COVID-19 [Internet]. Seoul: Korea Centers for Disease Control and Prevention, c2020 [cited 2020 Apr 23]. Available from: http://ncov.mohw. go.kr/baroView4.do?brdId=4\&brdGubun $=44$.

56. Korea Centers for Disease Control and Prevention. Social distancing [Internet]. Seoul: Korea Centers for Disease Control and Prevention, c2020 [cited 2020 Apr 23]. Available from: http://ncov.mohw.go.kr/guidelineList.do? brdId $=6 \&$ brdGubun $=61 \&$ dataGubun $=611$.

57. World Health Organization. Coronavirus disease (COVID-19) advice for the public [Internet]. Geneva: World Health Organization, c2020 [cited 2020 Apr 23]. Available from: https:// www.who.int/emergencies/diseases/novel-coronavirus2019/advice-for-public.

58. Centers for Disease Control and Prevention. How to protect yourself \& others [Internet]. Atlanta (GA): Centers for Disease Control and Prevention, c2020 [cited 2020 Apr 23]. Available from: https://www.cdc.gov/coronavirus/ 2019-ncov/prevent-getting-sick/prevention.html.

59. National Health Service. Social distancing: what you need to do [Internet]. Leeds: National Health Service, c2020 [cited 2020 May 28]. Available from: https://www. nhs.uk/conditions/coronavirus-covid-19/staying-athome-to-avoid-getting-coronavirus/staying-at-homeand-away-from-other-people/. 
60. Sveaas SH, Smedslund G, Hagen KB, Dagfinrud H. Effect of cardiorespiratory and strength exercises on disease activity in patients with inflammatory rheumatic diseases: a systematic review and meta-analysis. Br J Sports Med 2017;51:1065-72.

61. Agca R, Heslinga SC, Rollefstad S, Heslinga M, McInnes IB, Peters MJ, et al. EULAR recommendations for cardiovascular disease risk management in patients with rheumatoid arthritis and other forms of inflammatory joint disorders: 2015/2016 update. Ann Rheum Dis 2017;76:17-28

62. Rausch Osthoff AK, Niedermann K, Braun J, Adams J, Brodin N, Dagfinrud H, et al. 2018 EULAR recommendations for physical activity in people with inflammatory arthritis and osteoarthritis. Ann Rheum Dis 2018;77:1251-60.

63. Garber CE, Blissmer B, Deschenes MR, Franklin BA, Lamonte MJ, Lee IM, et al.; American College of Sports Medicine. American College of Sports Medicine position stand. Quantity and quality of exercise for developing and maintaining cardiorespiratory, musculoskeletal, and neuromotor fitness in apparently healthy adults: guidance for prescribing exercise. Med Sci Sports Exerc 2011;43: 1334-59.

64. Ahmadinejad Z, Alijani N, Mansori S, Ziaee V. Common sports-related infections: a review on clinical pictures, management and time to return to sports. Asian J Sports Med 2014;5:1-9.

65. Halabchi F, Ahmadinejad Z, Selk-Ghaffari M. COVID-19 epidemic: exercise or not to exercise; that is the question! Asian J Sports Med 2020;11:e102630.

66. World Health Organization. Q\&A: be active during COVID-19 [Internet]. Geneva: World Health Organization, c2020 [cited 2020 Apr 23]. Available from: https://www. who.int/news-room/q-a-detail/be-active-during-covid19.

67. Hartmann-Boyce J, Lindson N. Smoking in acute respiratory infections [Internet]. Oxford: Centre for EvidenceBased Medicine, c2020 [cited 2020 Apr 23]. Available from: https://www.cebm.net/covid-19/smoking-in-acuterespiratory-infections/.

68. World Health Organization. Tobacco and waterpipe use increases the risk of COVID-19 [Internet]. Geneva: World Health Organization, c2020 [cited 2020 Apr 23]. Available from: http://www.emro.who.int/tfi/know-the-truth/tobaccoand-waterpipe-users-are-at-increased-risk-of-covid19-infection.html.

69. Vardavas CI, Nikitara K. COVID-19 and smoking: a systematic review of the evidence. Tob Induc Dis 2020;18:20.

70. Berlin I, Thomas D, Le Faou AL, Cornuz J. COVID-19 and smoking. Nicotine Tob Res 2020;22:1650-2.

71. Freund KM, Belanger AJ, D'Agostino RB, Kannel WB. The health risks of smoking. The Framingham study: 34 years of follow-up. Ann Epidemiol 1993;3:417-24.

72. Will JC, Galuska DA, Ford ES, Mokdad A, Calle EE. Cigarette smoking and diabetes mellitus: evidence of a positive association from a large prospective cohort study. Int J Epidemiol 2001;30:540-6.

73. Komiyama M, Hasegawa K. Smoking cessation as a public health measure to limit the coronavirus disease 2019 pandemic. Eur Cardiol 2020;15:e16.
74. Sopori M. Effects of cigarette smoke on the immune system. Nat Rev Immunol 2002;2:372-7.

75. Sugiyama D, Nishimura K, Tamaki K, Tsuji G, Nakazawa $\mathrm{T}$, Morinobu A, et al. Impact of smoking as a risk factor for developing rheumatoid arthritis: a meta-analysis of observational studies. Ann Rheum Dis 2010;69:70-81.

76. Formica MK, Palmer JR, Rosenberg L, McAlindon TE. Smoking, alcohol consumption, and risk of systemic lupus erythematosus in the Black Women's Health Study. J Rheumatol 2003;30:1222-6.

77. Chasset F, Francès C, Barete S, Amoura Z, Arnaud L. Influence of smoking on the efficacy of antimalarials in cutaneous lupus: a meta-analysis of the literature. J Am Acad Dermatol 2015;72:634-9.

78. Piette EW, Foering KP, Chang AY, Okawa J, Ten Have TR, Feng R, et al. Impact of smoking in cutaneous lupus erythematosus. Arch Dermatol 2012;148:317-22.

79. Tam LS, Wei JC, Aggarwal A, Baek HJ, Cheung PP, Chiowchanwisawakit P, et al. 2018 APLAR axial spondyloarthritis treatment recommendations. Int J Rheum Dis 2019;22:340-56.

80. Kim D, Quinn J, Pinsky B, Shah NH, Brown I. Rates of co-infection between SARS-CoV-2 and other respiratory pathogens. JAMA 2020;323:2085-6.

81. Wu X, Cai Y, Huang X, Yu X, Zhao L, Wang F, et al. Co-infection with SARS-CoV-2 and influenza A virus in patient with pneumonia, China. Emerg Infect Dis 2020;26: 1324-6.

82. Chen N, Zhou M, Dong X, Qu J, Gong F, Han Y, et al. Epidemiological and clinical characteristics of 99 cases of 2019 novel coronavirus pneumonia in Wuhan, China: a descriptive study. Lancet 2020;395:507-13.

83. Cox MJ, Loman N, Bogaert D, O'Grady J. Co-infections: potentially lethal and unexplored in COVID-19. Lancet Microbe 2020;1:e11.

84. Arokiaraj MC. Correlation of influenza vaccination and influenza incidence on COVID-19 severity [Internet]. Rochester (NY): Social Science Research Network (SSRN), c2020 [cited 2020 Apr 23]. Available from: https://papers.ssrn.com/sol3/Papers.cfm?abstract_id $=3572814$.

85. Furer V, Rondaan C, Heijstek MW, Agmon-Levin N, van Assen S, Bijl M, et al. 2019 update of EULAR recommendations for vaccination in adult patients with autoimmune inflammatory rheumatic diseases. Ann Rheum Dis 2020;79:39-52.

86. O’Mahony R, Richards A, Deighton C, Scott D. Withdrawal of disease-modifying antirheumatic drugs in patients with rheumatoid arthritis: a systematic review and meta-analysis. Ann Rheum Dis 2010;69:1823-6.

87. Galvao TF, Zimmermann IR, da Mota LM, Silva MT, Pereira MG. Withdrawal of biologic agents in rheumatoid arthritis: a systematic review and meta-analysis. Clin Rheumatol 2016;35:1659-68.

88. LaRochelle GE Jr, LaRochelle AG, Ratner RE, Borenstein DG. Recovery of the hypothalamic-pituitary-adrenal (HPA) axis in patients with rheumatic diseases receiving low-dose prednisone. Am J Med 1993;95:258-64.

89. Joseph RM, Hunter AL, Ray DW, Dixon WG. Systemic glucocorticoid therapy and adrenal insufficiency in adults: a systematic review. Semin Arthritis Rheum 2016;46: $133-41$. 
90. Hoes JN, Jacobs JW, Boers M, Boumpas D, Buttgereit F, Caeyers N, et al. EULAR evidence-based recommendations on the management of systemic glucocorticoid therapy in rheumatic diseases. Ann Rheum Dis 2007;66:1560-7.

91. Voiriot G, Philippot Q, Elabbadi A, Elbim C, Chalumeau M, Fartoukh M. Risks related to the use of non-steroidal anti-inflammatory drugs in community-acquired pneumonia in adult and pediatric patients. J Clin Med 2019;8:786.

92. Day M. Covid-19: ibuprofen should not be used for managing symptoms, say doctors and scientists. BMJ 2020; 368:m1086

93. National Institute for Health and Care Excellence. COVID-19 rapid guideline: rheumatological autoimmune, inflammatory and metabolic bone disorders [Internet]. London: National Institute for Health and Care Excellence, c2020 [cited 2020 Apr 23]. Available from: https://www. nice.org.uk/guidance/ng167.

94. Torjesen I. Covid-19: NICE advises against using NSAIDs for fever in patients with suspected cases. BMJ 2020; 369:m1409.

95. Little P. Non-steroidal anti-inflammatory drugs and covid-19. BMJ 2020;368:m1185.

96. Torjesen I. Covid-19: ibuprofen can be used for symptoms, says UK agency, but reasons for change in advice are unclear. BMJ 2020;369:m1555.

97. World Health Organization. The use of non-steroidal anti-inflammatory drugs (NSAIDs) in patients with COVID-19 [Internet]. Geneva: World Health Organization, c2020 [cited 2020 Apr 23]. Available from: https://www.who.int/ news-room/commentaries/detail/the-use-of-non-steroidalanti-inflammatory-drugs-(nsaids)-in-patients-with-covid19.

98. EMA advice on the use of NSAIDs for Covid-19. Drug Ther Bull 2020;58:69.

99. Giollo A, Adami G, Gatti D, Idolazzi L, Rossini M. Coronavirus disease 19 (Covid-19) and non-steroidal anti-inflammatory drugs (NSAID). Ann Rheum Dis 2020 Apr 22 [Epub]. DOI:10.1136/annrheumdis-2020-217598.

100. Chen D, Li H, Xie J, Zhan Z, Liang L, Yang X. Herpes zoster in patients with systemic lupus erythematosus: clinical features, complications and risk factors. Exp Ther Med 2017;14:6222-8.

101. Kim SH, Hong SB, Yun SC, Choi WI, Ahn JJ, Lee YJ, et al.; Korean Society of Critical Care Medicine H1N1 Collaborative. Corticosteroid treatment in critically ill patients with pandemic influenza A/H1N1 2009 infection: analytic strategy using propensity scores. Am J Respir Crit Care Med 2011;183:1207-14.

102. Hui DS. Systemic corticosteroid therapy may delay viral clearance in patients with Middle East respiratory syndrome coronavirus infection. Am J Respir Crit Care Med 2018;197:700-1.

103. Russell CD, Millar JE, Baillie JK. Clinical evidence does not support corticosteroid treatment for 2019-nCoV lung injury. Lancet 2020;395:473-5.

104. Singh AK, Majumdar S, Singh R, Misra A. Role of corticosteroid in the management of COVID-19: a systemic review and a clinician's perspective. Diabetes Metab Syndr 2020;14:971-8

105. Wang Y, Ao G, Qi X, Zeng J. The influence of corticosteroid on patients with COVID-19 infection: a meta-analysis. Am
J Emerg Med 2020 Jun 23 [Epub]. DOI:10.1016/j.ajem. 2020.06.040.

106. Mehta B, Pedro S, Ozen G, Kalil A, Wolfe F, Mikuls T, et al. Serious infection risk in rheumatoid arthritis compared with non-inflammatory rheumatic and musculoskeletal diseases: a US national cohort study. RMD Open 2019; 5:e000935.

107. Blumentals WA, Arreglado A, Napalkov P, Toovey S. Rheumatoid arthritis and the incidence of influenza and influenza-related complications: a retrospective cohort study. BMC Musculoskelet Disord 2012;13:158.

108. Ledingham J, Gullick N, Irving K, Gorodkin R, Aris M, Burke J, et al. BSR and BHPR guideline for the prescription and monitoring of non-biologic disease-modifying anti-rheumatic drugs. Rheumatology (Oxford) 2017;56: 2257.

109. Liang W, Guan W, Chen R, Wang W, Li J, Xu K, et al. Cancer patients in SARS-CoV-2 infection: a nationwide analysis in China. Lancet Oncol 2020;21:335-7.

110. Zhang L, Zhu F, Xie L, Wang C, Wang J, Chen R, et al. Clinical characteristics of COVID-19-infected cancer patients: a retrospective case study in three hospitals within Wuhan, China. Ann Oncol 2020;31:894-901.

111. Singh JA, Saag KG, Bridges SL Jr, Akl EA, Bannuru RR, Sullivan MC, et al.; American College of Rheumatology. 2015 American College of Rheumatology guideline for the treatment of rheumatoid arthritis. Arthritis Care Res (Hoboken) 2016;68:1-25.

112. Gossec L, Baraliakos X, Kerschbaumer A, de Wit M, McInnes I, Dougados M, et al. EULAR recommendations for the management of psoriatic arthritis with pharmacological therapies: 2019 update. Ann Rheum Dis 2020;79: 700-12.

113. Boyman O, Comte D, Spertini F. Adverse reactions to biologic agents and their medical management. Nat Rev Rheumatol 2014;10:612-27.

114. Singh JA, Cameron C, Noorbaloochi S, Cullis T, Tucker M, Christensen $\mathrm{R}$, et al. Risk of serious infection in biological treatment of patients with rheumatoid arthritis: a systematic review and meta-analysis. Lancet 2015;386:258-65.

115. Strangfeld A, Listing J, Herzer P, Liebhaber A, Rockwitz K, Richter C, et al. Risk of herpes zoster in patients with rheumatoid arthritis treated with anti-TNF-alpha agents. JAMA 2009;301:737-44.

116. Winthrop KL, Baddley JW, Chen L, Liu L, Grijalva CG, Delzell E, et al. Association between the initiation of anti-tumor necrosis factor therapy and the risk of herpes zoster. JAMA 2013;309:887-95.

117. Luo P, Liu Y, Qiu L, Liu X, Liu D, Li J. Tocilizumab treatment in COVID-19: a single center experience. J Med Virol 2020;92:814-8

118. Michot JM, Albiges L, Chaput N, Saada V, Pommeret F, Griscelli F, et al. Tocilizumab, an anti-IL-6 receptor antibody, to treat COVID-19-related respiratory failure: a case report. Ann Oncol 2020;31:961-4.

119. Zhang C, Wu Z, Li JW, Zhao H, Wang GQ. Cytokine release syndrome in severe COVID-19: interleukin-6 receptor antagonist tocilizumab may be the key to reduce mortality. Int J Antimicrob Agents 2020;55:105954.

120. Xu X, Han M, Li T, Sun W, Wang D, Fu B, et al. Effective treatment of severe COVID-19 patients with tocilizumab. 
Proc Natl Acad Sci U S A 2020;117:10970-5.

121. Buonaguro FM, Puzanov I, Ascierto PA. Anti-IL6R role in treatment of COVID-19-related ARDS. J Transl Med 2020;18:165.

122. Fu B, Xu X, Wei H. Why tocilizumab could be an effective treatment for severe COVID-19? J Transl Med 2020; 18:164.

123. Nicastri E, Petrosillo N, Ascoli Bartoli T, Lepore L, Mondi A, Palmieri F, et al. National Institute for the Infectious Diseases "L. Spallanzani", IRCCS. Recommendations for COVID-19 clinical management. Infect Dis Rep 2020;12: 8543.

124. Richardson P, Griffin I, Tucker C, Smith D, Oechsle O, Phelan A, et al. Baricitinib as potential treatment for 2019-nCoV acute respiratory disease. Lancet 2020;395: e30-1.

125. Richardson PJ, Corbellino M, Stebbing J. Baricitinib for COVID-19: a suitable treatment? - authors' reply. Lancet Infect Dis 2020;20:1013-4.

126. Favalli EG, Biggioggero M, Maioli G, Caporali R. Baricitinib for COVID-19: a suitable treatment? Lancet Infect Dis 2020;20:1012-3.

127. Zhang W, Zhao Y, Zhang F, Wang Q, Li T, Liu Z, et al. The use of anti-inflammatory drugs in the treatment of people with severe coronavirus disease 2019 (COVID-19): the perspectives of clinical immunologists from China. Clin Immunol 2020;214:108393.

128. Russell B, Moss C, George G, Santaolalla A, Cope A, Papa $S$, et al. Associations between immune-suppressive and stimulating drugs and novel COVID-19-a systematic review of current evidence. Ecancermedicalscience 2020;14: 1022.

129. Praveen D, Puvvada RC, M VA. Janus kinase inhibitor baricitinib is not an ideal option for management of COVID-19. Int J Antimicrob Agents 2020;55:105967.

130. Pawar A, Desai RJ, Gautam N, Kim SC. Risk of admission to hospital for serious infection after initiating tofacitinib versus biologic DMARDs in patients with rheumatoid arthritis: a multidatabase cohort study. Lancet Rheumatol 2020;2:E84-98.

131. Favalli EG. Tofacitinib's infectious profile: concerns for clinical practice. Lancet Rheumatol 2020;2:E65-7.

132. Anderson DM, Maraskovsky E, Billingsley WL, Dougall WC, Tometsko ME, Roux ER, et al. A homologue of the TNF receptor and its ligand enhance T-cell growth and dendritic-cell function. Nature 1997;390:175-9.

133. Padigel UM, Kim N, Choi Y, Farrell JP. TRANCE-RANK costimulation is required for IL-12 production and the initiation of a Th1-type response to Leishmania major infection in CD40L-deficient mice. J Immunol 2003;171: 5437-41.

134. Barbaroux JB, Beleut M, Brisken C, Mueller CG, Groves RW. Epidermal receptor activator of NF-kappaB ligand controls Langerhans cells numbers and proliferation. J Immunol 2008;181:1103-8.

135. Loser K, Mehling A, Loeser S, Apelt J, Kuhn A, Grabbe S, et al. Epidermal RANKL controls regulatory T-cell numbers via activation of dendritic cells. Nat Med 2006;12:1372-9.

136. Cummings SR, San Martin J, McClung MR, Siris ES, Eastell R, Reid IR, et al.; FREEDOM Trial. Denosumab for prevention of fractures in postmenopausal women with osteoporosis. N Engl J Med 2009;361:756-65.

137. Wensel TM, Iranikhah MM, Wilborn TW. Effects of denosumab on bone mineral density and bone turnover in postmenopausal women. Pharmacotherapy 2011;31:510-23.

138. Miller PD, Bolognese MA, Lewiecki EM, McClung MR, Ding B, Austin M, et al.; Amg Bone Loss Study Group. Effect of denosumab on bone density and turnover in postmenopausal women with low bone mass after long-term continued, discontinued, and restarting of therapy: a randomized blinded phase 2 clinical trial. Bone 2008; 43:222-9.

139. Cummings SR, Ferrari S, Eastell R, Gilchrist N, Jensen JB, McClung $M$, et al. Vertebral fractures after discontinuation of denosumab: a post hoc analysis of the randomized placebo-controlled FREEDOM trial and its extension. J Bone Miner Res 2018;33:190-8.

140. Anastasilakis AD, Polyzos SA, Makras P, Aubry-Rozier B, Kaouri S, Lamy O. Clinical features of 24 patients with rebound-associated vertebral fractures after denosumab discontinuation: systematic review and additional cases. J Bone Miner Res 2017;32:1291-6.

141. Lamy O, Gonzalez-Rodriguez E, Stoll D, Hans D, AubryRozier B. Severe rebound-associated vertebral fractures after denosumab discontinuation: 9 clinical cases report. J Clin Endocrinol Metab 2017;102:354-8.

142. Doran MF, Crowson CS, Pond GR, O'Fallon WM, Gabriel $S E$. Frequency of infection in patients with rheumatoid arthritis compared with controls: a population-based study. Arthritis Rheum 2002;46:2287-93.

143. Doaty S, Agrawal H, Bauer E, Furst DE. Infection and lupus: which causes which? Curr Rheumatol Rep 2016; 18:13.

144. Zandman-Goddard G, Shoenfeld Y. Infections and SLE. Autoimmunity 2005;38:473-85.

145. Koetz K, Bryl E, Spickschen K, O’Fallon WM, Goronzy JJ Weyand CM. T cell homeostasis in patients with rheumatoid arthritis. Proc Natl Acad Sci U S A 2000;97:9203-8.

146. Fessler J, Raicht A, Husic R, Ficjan A, Duftner C, Schwinger W, et al. Premature senescence of T-cell subsets in axial spondyloarthritis. Ann Rheum Dis 2016;75:748-54.

147. Segal BH, Sneller MC. Infectious complications of immunosuppressive therapy in patients with rheumatic diseases. Rheum Dis Clin North Am 1997;23:219-37.

148. Zhang X, Tan Y, Ling Y, Lu G, Liu F, Yi Z, et al. Viral and host factors related to the clinical outcome of COVID-19. Nature 2020;583:437-40.

149. Gianfrancesco M, Hyrich KL, Al-Adely S, Carmona L, Danila MI, Gossec L, et al.; COVID-19 Global Rheumatology Alliance. Characteristics associated with hospitalisation for COVID-19 in people with rheumatic disease: data from the COVID-19 Global Rheumatology Alliance physician-reported registry. Ann Rheum Dis 2020;79:859-66.

150. Williamson EJ, Walker AJ, Bhaskaran K, Bacon S, Bates C, Morton CE, et al. Factors associated with COVID-19-related death using OpenSAFELY. Nature 2020;584:430-6.

151. Pablos JL, Abasolo L, Alvaro-Gracia JM, Blanco FJ, Blanco R, Castrejón I, et al.; RIER investigators group. Prevalence of hospital PCR-confirmed COVID-19 cases in patients with chronic inflammatory and autoimmune rheumatic diseases. Ann Rheum Dis 2020;79:1170-3.

152. Hasell J. Testing early, testing late: four countries' ap- 
proaches to COVID-19 testing compared [Internet]. Oxford: Our World in Data, c2020 [cited 2020 May 19]. Available from: https://ourworldindata.org/covid-testing-us-uk-korea-italy.

153. Peck KR. Early diagnosis and rapid isolation: response to COVID-19 outbreak in Korea. Clin Microbiol Infect 2020;26:805-7.
154. Chu DK, Akl EA, Duda S, Solo K, Yaacoub S, Schünemann HJ; COVID-19 Systematic Urgent Review Group Effort (SURGE) study authors. Physical distancing, face masks, and eye protection to prevent person-to-person transmission of SARS-CoV-2 and COVID-19: a systematic review and meta-analysis. Lancet 2020;395:1973-87. 